\title{
LEARNING UNVEILED: REFLECTING ON UNEXPECTED OUTCOMES FROM COVID-I9
}

\author{
Emma Collins and Josie Crawley
}

\section{INTRODUCTION}

The COVID-19 pandemic caused significant upheaval for the education of nursing students globally, particularly in 2020. In Otago, New Zealand, unexpected student learning unfolded from students' completing an interrupted clinical placement after a significant hiatus. Students returning to the same placement (with the same supporting clinical lecturer), after eight months of alternate learning, achieved a growth in knowledge, practice and confidence in a way that a student's placement in a new practice area did not. Employing the Rolfe, Freshwater and Jasper model of reflective learning (200I, 2010), this article describes this situation, reflects on student feedback and explores the implications for future education, including lecturers' responses to this phenomenon.

\section{THE ROLFE, FRESHWATER AND JASPER REFLECTION MODEL}

The Rolfe, Freshwater and Jasper model of reflective learning $(2001,2010)$ is an uncomplicated model of reflection, providing a simple framework for nurses and health professionals to work through the process of reflection. The process has three phases: What?, So what? and Now what? (building on Borton's (1970) model incorporating the same three questions). These stages provide the framework for learning from reflection - a process whereby past events are recalled to recapture the experience and the observed outcomes are analysed from multiple perspectives, providing a foundation for identifying and planning future improvements (Schon, 1991). While Rolfe et al. (2010) subsequently provided more prescriptive questions to be asked at each process stage, the flexibility of the model remains (Skinner and Mitchell, 2016).

Rolfe, Freshwater and Jasper (2010) explain that the first part of the process, "What?," is mostly descriptive. This includes observation of what happened and the outcome for participants (the student, the lecturer, the placement site), including descriptions of emotive states. The second stage, "So What?," encompasses the analytical part of the reflective process - what meaning does the experience hold? Ideally, consultation of both literature and others involved (in our case, the students) occurs at this stage in order to consolidate multiple perspectives on the situation. The final phase looks to the future, creating and implementing a proactive plan. "Now what?" requires participants to explore the broader implications of the situation and consider what steps to take to respond to learning, in our case to create and action a plan that will build teaching/learning and nursing practice.

Jasper (2013) argues that applying the Rolfe et al. (2010) model consistently results in a reflective learning process where experience is valued by creating higher levels of self-awareness, with the second and third stages supporting the incorporation of theoretical knowledge into practice, thereby enabling ongoing quality improvement. 


\section{WHAT?}

This is the story of part of our COVID-19 response with the Year 2 Bachelor of Nursing team at Otago Polytechnic. Globally, 2020 was a tumultuous year and, like everyone else, we did not know where this pandemic was going. It was a rapidly evolving landscape and tertiary institutions were adapting to a new way of life, as were governments, district health boards and non-governmental organisations. Like the rest of the world, the programme for the Bachelor of Nursing Year 2 learners was significantly interrupted.

Our learners were on their first placement for the year in a variety of clinical areas (mental health, community, senior persons' and acute care settings) when they were told to cease their placement and observe the Levels 3 and 4 lockdowns in March 2020. This resulted in a great deal of stress for the learners, as well as for teaching staff and the clinical placement areas. Many learners had completed only one week of placement, while others had completed over two weeks out of three. However, the familiarising week of orientation had taken place, and learners were just beginning to see their potential practice when it was withdrawn. While withdrawal from placement was abrupt, it followed several days of disrupted practice - for example, learners turning up to a clinical placement and being told by staff to go home, then being contacted again to come in.

For those in all settings, the week beginning 16 March 2020 was an unprecedented time of enormous uncertainty and constant stress, with alerts announcing rapidly changing levels at short notice. It was originally unclear if learner nurses were deemed to be essential staff by the Ministry of Health, or which health facilities and services would be required to stay open, given that we were preparing for a potential, perhaps deadly, epidemic within Aotearoa New Zealand's borders. At Level 2, learners in most senior persons' areas were immediately shut out (by the facilities themselves), while some community-based placements which were setting up COVID-19 testing stations asked if learners could continue to work through.

Our focus was on ensuring that learners were safe, ideally home with family and/or friends. Staff also needed to be safe and secure and, once that was dealt with, it was a time of reorganising theory and clinical placements. This involved checking in with learners individually, as well as in groups, to keep them fully informed of what was happening with their learning and checking that they were safe.

Learners returned to their theory learning in May 2020, dispersing to their pre-planned clinical placement locations in late May. In November, after their end-of-year exams, learners returned (mostly) to the same clinical area that they had left in March to complete their learning experience. Some learners had 3-4 shifts to complete and others had many more. This took a significant amount of planning and partnership with clinical areas. The learners had had eight months away from their clinical areas, and during this time had completed three other clinical placement experiences. Learners had never returned to a clinical area before during their Year 2 placements.

\section{SO WHAT?}

Returning to the interrupted clinical placements which had started in March was problematic for both staff, learners and placements. Staff at clinical placement areas were exhausted after an uncertain year, were experiencing staffing shortages and high-acuity patients, and were working to make up backlogs from COVID-19, all under high stress conditions. The potential for changing alert levels was still very real. Learners were also anxious about returning to their clinical area, delaying their end-of-year break which resulted in financial hardship for some. They were tired from the year they had had and very much wanted it to be over. However, learners were all offered placements, and welcomed back to their original facility. This initiated a very positive experience with which to conclude an overwhelming year. The positive welcome they received was a surprise - the placements were very hard to organise as organisations did not want to commit themselves when conditions could change with 24 hours' notice; they also felt that student learning would be compromised by adapted practice, such as increased reliance on telehealth. 
During the November/December placements the lecturing staff supporting the learners in their clinical placements were hearing that they were enjoying this placement and were finding it to be a very rewarding and uplifting experience. These were unprompted responses from the learners and the nurses they worked with. By returning to the same clinical area after eight months' alternate learning, learners could appreciate the growth in their learning, confidence, knowledge and skills that had occurred during this time. This prompted the lecturing staff to reflect on this phenomenon further, both with their learners and between themselves, generating much reflection on the learners' experiences and potential modifications to their learning journey.

Previously, lecturers had viewed returning to the same area as limiting learners' exposure to practice, and had sought to provide a range of experiences. Some lecturers felt that the orientation week was the most stressful week of clinical and, with that under their belt, learners should be able to slip into their placement routines. Had the placement been completed any later, learners may have expected to be working within the Year 3 scope of practice, and would have required re-orientation into their areas. The point was also made that each clinical course is siloed as a separate course. Lecturers often get learners to reflect verbally about their learning from the beginning to the end of placement (a four-week period); however, learning from previous courses is not normally visible, unless the learner had required additional support to complete the placement. By returning to the same placement, with the same supervising lecturer, students, lecturers and nurses could look at the objectives learners had set themselves in March, and see that their practice had already grown to encompass these.

Nurses supervising in placements provided solicited feedback to the learners' supervising lecturer. Many shared that they really enjoyed having the learners back, noting that seeing an individual learner's growth in skills, confidence and learning across the year added value to their preceptorship. Some nurses commented that it validated the belief that learners do learn from being with them.

Staff talked with the learners that they were working with and reflected on the experience that they had had, with the learners and with each other. Discussions between faculty staff determined that there were a number of considerations to the learners journey that were emerging.

Learners felt that they could "see" the difference in themselves compared with eight months earlier when they were in the same environment. Being in the same placement area with the same scope expectations enabled learners to notice a change and a progression in their clinical practice and knowledge base. They felt that it was much easier to see the learning that they had engaged with over the year and how this was able to be applied to the clinical context. This was an uplifting and rewarding experience, for learners as well as for staff, and learners found it very motivating. Sargeant et al. (20II) found that learners self-monitor when learning in practice, reflecting during and after activities, suggesting an integrative process of self-assessment, drawing on all relevant experience to date. The frequent use of the word "see" by respondents implies observing, noticing, thinking about, becoming aware of - suggesting that this experience engaged them in reflective learning. Hay, Kinchin and Lygo-Baker (2008) state that in tertiary settings, only the learner can make learning meaningful, defining learning as the perception of personal change. Returning to the same environment provided an experiential opportunity that illuminated learners' growth in the knowledge and skills gained from their first experience through to their delayed completion through the integration of new material from other placements, resulting in meaningful learning. They were able to reflect on their competency development, and could "see" the personal change that had occurred.

After an additional eight months of learning, the learners felt a lot more confident about their skills and clinical abilities. This was very visible to them as they returned to the same clinical area and were doing many of the same tasks. Some learners commented that they felt a lot more confident compared to the start of the year, in particular with certain nursing skills, as well as how they were able to interact with patients and staff. For the learners, this was a catalyst for developing self-efficacy, a belief in one's ability to take action or, in a nursing context, to manage clinical tasks (Stump et al., 2012). Many had also been part of developing COVID-19 contingency plans in Marchwhich had come to fruition - and they then worked within them in November/December. 
Learners also found that returning to their clinical placements was motivating. Through the visibility of the experience and the confidence that was gained, motivation increased and this, we believe, put the learners in a good position for their final year of their degree. Motivation is important in learning because motivated learners tend to engage in activities that help them learn, as well as helping them to achieve in academic settings (Jones, 2009). Therefore, we want our learners to be highly motivated, and for them to motivate themselves what happened with this placement is even more desirable.

Many of the learners felt that they could see how much their clinical skills had improved over the year. This was in part due to their developing confidence, but also their self-development and motivation. The development of clinical skills is important in a Bachelor of Nursing programme and teachers are constantly looking for ways to develop skills, especially when clinical experience may be limited. It was important that the learners did not miss out on this clinical experience, as research has shown that clinical experiences give learners more confidence in their ability to perform skills and other behaviours in the clinical environment (George et al., 2020). Many learners simply felt more comfortable going back into this clinical environment, right from the beginning. They also felt significantly reduced anxiety levels compared to when they normally commenced a placement. Feeling more comfortable heading into their clinical placement allowed them to make the most of the learning opportunities available to them, and to utilise their time there well. A study by Doyle et al. (2017) discusses the importance of learners feeling comfortable in clinical placement. They state that the culture of the nursing unit has the most impact on satisfaction rates for learners by making them feel comfortable (p. 30). It was important to these learners that they were comfortable returning to these clinical areas:

Learners enjoyed going back to their clinical areas, seeing how much they had improved and reconnecting with their clinical preceptors. They enjoyed seeing some of the same residents from their first placement and revisiting objectives that had been set earlier in the year - objectives that had initially seemed daunting, and now had to be revisited and were even more challenging. The positivity and enjoyment that came out of this learning made a great end to the year. Gomez, Wu and Passerini (2010, as cited in Lin et al., 2020) state that when learners feel that the learning experience is pleasurable for them, they perceive enjoyment. Therefore as educators, we are constantly trying to ensure that our learners' experiences are enjoyable.

Although we mainly reflected on positive experiences from this catch-up placement, some learners reflected with sadness as residents who were present at the beginning of the year had since passed away. While this situation was an unavoidable and sad consequence of the placement for this learner, it also demonstrates their connectedness to this particular clinical area and the team.

\section{NOW WHAT?}

Our 2020 revisit was an exhaustive crisis response to complete learners' placement hours and enable Year 2 learners to progress to Year 3 of their Bachelor of Nursing degree. Currently, the New Zealand Nursing Council requires breadth of exposure to varied clinical experience settings, while our model of delivery provides different learning methods. However, when we silo practice areas we restrict the visibility of learning to the student, and potentially restrict lecturer support to best scaffold student learning. For learners, once a course is passed, that course work is put aside to focus on another course. For lecturers, with a new group of 30 learners four times a year, the majority of learners arrive as a clean slate.

Depth of student learning and growth is reliant on the learner being able to consolidate competency learning across different areas of practice through introspective self-awareness. Although it is likely that some learners do this independently, it has not previously been reported to lecturers as an achievement that learners and placements are actively celebrating in their fourth placement. Student learning and enjoyment from revisiting practice in the COVID-19 make-up placements is an opportunity to improve future practice. 
Did this unexpected response to COVID-19 imply that curricula should be designed to include revisiting a clinical area in order to illuminate growth in professional practice? As the School of Nursing is at the beginning of a fiveyearly curriculum review cycle, there is limited scope for significant changes to curricula. The introduction of a fifth placement, or a split first placement, involves costs in organising placements, reduced lecturer cover due to leave, an extended financial student year, placement burnout and a disinclination to take new learners the following March (as it feels to staff that they have only just left).

Unable to change curricula at this stage, nurse lecturers have explored options that will engage each learner, making explicit their own learning journey. Having one lecturer assigned to a learner across all different settings would mean that the learning journey will now be very visible, with clear scaffolding opportunities for learning; however, this arrangement would undermine lecturer knowledge of specialty areas, be detrimental to placement relationships and increase lecturer workload. Alternatively, the option of building in mentoring with a group of 30 learners, who check in with a consistent lecturer after each clinical placement, is still being explored.

However, the teaching team involved have already found other ways to incorporate this learning into current teaching and learning contexts. Three initiatives have been developed and put in place to break down the silos between the clinical courses, and to help engage learners across the year by increasing learning visibility to both learners and lecturers.

The first initiative involves forming an objective at the end of one placement for achievement in the next placement, which is recorded on the learner's summative form. Learners are encouraged to share this objective with the lecturer in the following placement, but are also referred to it in the preparatory week before their next placement. For most courses, this objective has become part of the introductory session for the next placement.

Secondly, a written requirement for each separate clinical placement student portfolio has been introduced: the provision of learner self-assessment exemplars against the ten course outcomes. These outcomes are consistent across the Year 2 clinical courses and reflect the competencies learners must demonstrate under Nursing Council requirements. In 2020 this learning was siloed in four separate clinical courses, each with its own digital platform. In 2021, lecturers combined student self-assessments against course outcomes/competencies into one single document. Currently, this document is uploaded to each clinical course digital portfolio, added to and reloaded for the next, until all four placement exemplars are together on the one form by the end of the year.

Combining these exemplars has shifted the focus from one-off practice evidence to growing learner competency and scope of practice assessed across a range of placements. This is now a space where learners can chart their learning against a particular competency for each placement across the year, and engage in reflective practice by looking at their earlier examples. This increases the visibility of previous and current learning to both learner and lecturer, as well as highlighting areas where practice needs to grow. There are opportunities to discuss this learning in the summative assessment of the clinical course, in a 30-minute one-on-one session celebrating the student's learning. Future developments aimed at breaking down silos may include using an ePortfolio digital platform, where a single clinical portfolio may be added to across the year while maintaining course independence.

The third initiative is a hand-over meeting of clinical course co-ordinators before finalising the next student placements. Traditionally in nursing handovers, nurses comment on patients' progress and any potential new challenges. These meetings adapt this practice to the learning environment so that learners are more intentionally matched to a placement based on individual requirements, and systems can be put in place to support learner health, wellbeing and learning before the next placement, thus increasing opportunities for positive learning. 


\section{CONCLUSION}

While COVID-19 has forever changed nursing practice, there have been some positive experiences. Lecturers have learned that there may be strengths in nursing students returning to the same placement after consolidating learning in other courses, reducing concerns if a learner is assigned to the same placement area in Years I and 2. If they are, it may be useful to assign the same supervising lecturer and ensure that placements are not back-to-back. Because of logistical difficulties in arranging a repeat or split placement, alternative strategies to make student learning visible to learners and provide opportunities to scaffold student learning across placements have been implemented.

As lecturers, we have been reassured by our learners' experience in 2020 that learners are able to consolidate and build their learning across the four clinical courses, but we also believe that they may need lecturer assistance to make that learning visible to themselves. We have also been reminded that the tools we encourage students to use, such as reflective learning frameworks, can also be employed by lecturers to continually improve the quality of the learner experience. Seeing learners reflect on their growth in practice was a humbling and rewarding experience for staff, and led us to think about how this can be achieved in a post-COVID-19 learning environment, as illustrated in our action plan during 2021.

Emma Collins previously worked as a Principal Lecturer in the School of Nursing at Otago Polytechnic. Her current position is as Professional Practice Fellow at the Dunedin School of Medicine, University of Otago. Her research interests include digital health and teaching and learning with mixed reality technology.

(D) https://orcid.org/0000-0002-9406-4085

Josie Crawley is a Principal Lecturer at the School of Nursing, Otago Polytechnic. She has been involved in nurse education in both the community and institutions for nearly 30 years. Her research platform explores the place of narratives within nursing education for reflection, to build compassionate care and to research the client and student experience. She has published in a variety of academic journals, case studies, presented internationally, and her poetry has been included in a collection of poems by Aotearoa New Zealand Nurses. She is passionate about health promotion and is the co-editor of Stories of Nursing in Rural Aotearoa: A Landscape of Care.

(D) https://orcid.org/0000-0003-101।-3335

\section{REFERENCES}

Borton, T. (1970). Reach, touch and teach: Student concerns and process education. Hutchinson.

Doyle, K., Sainsbury, K., Cleary, S., Parkinson, L., Vindigni, D., McGrath, I., \& Cruickshank, M. (20I7). Happy to help/happy to be here: Identifying components of successful clinical placements for undergraduate nursing students. Nurse Education Today, 49, 27-32. https://doi.org/10.1016/j.nedt.2016.11.001

George, T. P., DeCristofaro, C., \& Ford Murphy, R. (2020). Self-efficacy and concerns of nursing students regarding clinical experiences. Nurse Education Today, 90, Article 10440 I. https://doi.org / 0. I0 I6/j.nedt.2020.10440 I

Hay, D., Kinchin, I., \& Lygo-Baker, S. (2008). Making learning visible: The role of concept mapping in higher education. Studies in Higher Education, 33(3). https://doi.org/l0.1080/0307507080204925।

Jasper, M. (2013). Beginning reflective practice. Cengage Learning.

Jones, B. D. (2009). Motivating students to engage in learning: The MUSIC model of academic motivation. International Journal of Teaching and Learning in Higher Education, 21(2), 272-285. 
Lin, C.-Y., Huang, C.-K., \& Ko, C.-J. (2020). The impact of perceived enjoyment on team effectiveness and individual learning in a blended learning business course: The mediating effect of knowledge sharing. Australasian Journal of Educational Technology, 36(I), 126-141. https://doi.org/10.14742/ajet.4446

Rolfe, G., Freshwater, D., \& Jasper, M. (200I). Critical reflection in nursing and the helping professions: A user's guide. Palgrave Macmillan.

Rolfe, G., Jasper, M., \& Freshwater, D. (2010). Critical reflection in practice: Generating knowledge for care (2nd ed.). Palgrave Macmillan.

Sargeant J. M., Eva, K. W., Armson, H., Chesluk, B., Dornan, T., Holmboe, E., Lockyer, J. M., Loney, E., Mann, K. V., \& van der Vleuten, C. P. M. (20II). Features of assessment learners use to make informed self-assessment of clinical performance. Medical Education, 45(6), 636-647.

Schon, D. (1991). The reflective practitioner. Jossey Bass.

Skinner, M., \& Mitchell, D. (2016). "What? So What? Now What?" Applying Borton and Rolfe's models of reflexive practice in healthcare contexts. Health and Social Care Chaplaincy, 4(I), 10-19. https://journals.equinoxpub.com/HSCC/article/ viewArticle/28972

Stump, G., Husman, J., \& Brem, S. (2012). The nursing student self-efficacy scale: Development using item response theory. Nursing Research, 61, 149-158. https://doi.org/I0.1097/NNR.0b013e318253a750 